\title{
Psychometric Properties of Nepali Translated Version of Preschool Anxiety Scale (Parent) Among Preschool Children in Nepal
}

Sabina Maharjan ( $\sim$ sabinamaharjan071@gmail.com )

Tribhuvan University

Mita Rana

Tribhuvan University

Bidusha Neupane

TPO Nepal

Sujan Rijal

University of Oslo

Suraj Shakya

Tribhuvan University

Pramesh Man Pradhan

Tribhuvan University

Saroj Prasad Ojha

Tribhuvan University

Kamal Gautam

TPO Nepal

\section{Research Article}

Keywords: Anxiety, Preschool Anxiety, Exploratory factor analysis, Confirmatory factor analysis

Posted Date: September 8th, 2021

DOI: https://doi.org/10.21203/rs.3.rs-823144/v1

License: (1) (1) This work is licensed under a Creative Commons Attribution 4.0 International License. Read Full License 


\section{Abstract \\ Background}

The Preschool Anxiety Scale (PAS) is a 28- item measure designed to assess anxiety symptoms in preschoolers aged 3 to 6 years. The aim of this study is to assess the psychometric properties of the Nepali translated version of the Preschool Anxiety Scale-Parent version, together with evidence on the reliability and cross-informant agreement among parents.

\section{Methods}

A descriptive cross-sectional design was used to collect data from 680 mothers among seven conveniently selected private schools in Kathmandu.

\section{Results}

Age groups and gender differences across PAS scales were found statistically significant in mother's reports. Exploratory factor analyses results suggest that the items of the PAS- Nepalese version do not reflect the five categories in anxiety in a clear way. This is particularly in separation anxiety, social phobia, and obsessive-compulsion. In confirmatory factor analysis, 28 items showed a poor fit of the five-factor original model for the data. However, removing three items ( 25 item version) through the five-factor model indicated a better fit. Internal consistency measured by Cronbach's alpha for the PAS-Parent version scale was of good range (0.87). Cronbach's alpha of the subscales: generalized anxiety (0.63), social phobia (0.67), physical injury fears (0.75), and Separation anxiety (0.63) were in fair range; while it was in poor range for the Obsessive-Compulsive subscale (0.567). Cross informant agreement on the ratings of anxiety symptoms of children by the fathers and mothers was low, as reflected by a weak positive correlation.

\section{Conclusion}

Nepalese version of the PAS demonstrated fair psychometric properties, supporting its utility in screening and assessing a broad range of anxiety symptoms in Nepalese pre-schoolers.

\section{Background}

Anxiety is a normal part of childhood, and every child goes through phases that can be characterized by persistent, irrational, overwhelming worries, fear, and anxiety that interfere with daily activities. Anxiety disorders are the most common class of mental disorders across development $(1,2)$ and the median age of onset was found to be 6 years for affected youth (3), hence this disorder begins very early in life. 
The prevalence of psychiatric disorder in pre-schooler estimate population rate for psychiatric disorder has been reported to be $7.1 \%$ (4). Prevalence of generalized anxiety disorder is reported around $0.6 \%$ and $6.5 \%$, separation anxiety disorder estimate ranges from $0.3-5.4 \%$, and social phobia range from $0.5-$ $4.4 \%(5)$.

Anxiety disorder studies show concerning stability over preschool period indicating that $34 \%$ of children with an anxiety disorder at age 3 and continue to meet criteria for diagnosis of age 6 (6). In longer-term, childhood anxiety disorder often follow a chronic or recurring course into adolescence and adulthood (7). Similarly, the prevalence of anxiety disorders in preschool-aged children is similar to children aged 5 to 17 years (8). Similarly, anxiety disorder would have predicted externalizing and internalizing childhood disorders such as depression and conduct disorder later in life (7).

There is a lack of study and human resources working specifically on mental health and anxiety among pre-schoolers in Nepal. One of the barriers to research into preschool anxiety is the lack of reliable and valid assessment devices. There are relatively little researches about anxiety problem among pre-schooler (9). The importance of developing adequate strategies for assessing and treating anxiety disorders in preschool-aged children is important to carry out. To the best of our knowledge, the Preschool Anxiety Scale (PAS) is the only measure that specifically assesses multiple anxiety symptoms in preschool-aged children (10). The PAS is a 28 items parent-report measure that was designed to assess anxiety dimensions specified in the DSM-IV. The factor structure and construct validity were examined in a large Australian community sample. Exploratory factor analysis revealed four or five factors and item was unclear whether separation anxiety and generalized anxiety represented discrete factors. Confirmatory factor analysis revealed five factors: separation anxiety disorder, physical injury fears, social phobia, obsessive-compulsive disorder and generalized anxiety disorder. The PAS scale shows good reliability and construct validity in community scale of children 3 to 5 years. Psychometric properties of the PAS have also been examined in Chinese (11), Dutch (12), Romanian (13), and Portuguese (Almeida \& Viana, 2013) children, being the original five-factor structure proposed by Spence et al(10) supported by most of these studies. A different structure, with a five-factor model that excludes the separation anxiety factor and includes two separate factors representing physical injury fears, has been found in a Dutch sample (14). Similarly, Benga et al. (13) also found that a four-factor or five-factor solutions provided a good fit for the data in a Romanian sample but due to small differences between these model and theoretical arguments, the authors preferred to maintain the original five-factor model. The study has not been conducted in Nepalese preschool children. A revised version of the PAS was tested by these different authors (15), also showing good psychometric properties and a different structure formed by four factors, excluding obsessive-compulsive disorder, in a sample of children between 3 and 5 years old. However, the original version has been more commonly used by international studies than revised version.

The primary purpose of this study was to examine anxiety disorder symptoms of Nepalese Preschool children in several ways: (1) to investigate the Psychometric properties of the Nepali translated version of Preschool Anxiety Scale -Parent version in private schools of Kathmandu. Internal consistency of total scale and subscale was assessed; (2) To translate Preschool Anxiety Scale-Parent version in Nepali; (3) 
To find out the factor structure of Preschool Anxiety Scale - Parent version; (4) To find out the reliability of Preschool Anxiety Scale -Parent version; (5) To find out the cross-informant agreement of mother and father; (6) To assess the relationship between socio-demographic factors and Anxiety of pre-schooler children.

\section{Methodology}

\section{Participants}

The sample consisted of 920 children (379 boys and 301 girls) aged between 3 to 6 years. The age distribution was as follows: $15.29 \%(n=104)$ were 3 years old; $22.2 \%(n=151)$ were 4 years old; $27.79 \%$ $(n=189)$ were 5 years old and $34.70 \%(n=236)$ were 6 years old. For collecting data, the assessment instrument was completed by their mother $(n=680)$ and for cross informant sample mother $(n=50)$ and father $(n=50)$. They were recruited from six schools in Kathmandu valley of Nepal. The schools were selected by a conveniently non-random sampling method. Most of the participants were in age groups of 26-30 years (36.3\%) whereas the least number of participants $(0.3 \%)$ were representing the age group of (15-20) years. About, $27.9 \%$ of the mothers reported that they were literate without formal education and only $8.6 \%$ had education till master level. The majority of the participants were housewives $(45.2 \%)$ and the least number of participants (3.7\%) were from government jobs. The majority of participants were from joint families (52.9\%). Only $7.79 \%$ of the mothers reported having a history of mental illness in their family.

\section{Measures}

\section{Preschool Anxiety Scale (PAS)}

The PAS is comprised of 28 items providing information about anxiety and worries in children from 3 to 6 of age. The PAS consists of five subscales: separation anxiety disorder, physical injury fears, social phobia, and obsessive-compulsive disorder, and generalized anxiety disorder, post-traumatic stress disorder. The participants were asked to rate the items of each subscale on a five-point scale ranging from 0 (not true at all) to 4 (very often true). Construct validity of the scale was good, showing a significant correlation between the total score of the PAS and a measure of internalizing disorders ( $r=$ 0.68 and $r=0.59$ for mothers and fathers, respectively) (10). The process of translation and adaption of the instrument is according to WHO. The original PAS-Parent version was translated from English to Nepali language, considering the suggestion made by the experts. Later, two experts were asked to translate back the PAS- Parent version from Nepali to English. The back-translated instrument was reviewed by the researchers to cross-check the content and meaning of each item between the backtranslated instruments (English) and the original instruments (English). The PAS- Parent version was revised by the researchers based on the feedback and recommendations from the two experts. Reviewer responses indicated that most PAS-Parent version items were adequately translated. Then it was applied to the 10 focused group mothers from the child guidance clinic for piloting to see respondent's actual responses to the instrument for consistency. The internal consistency of the PAS scale was 0.87 . The 
final revision of the Preschool Anxiety Scale -Parent version was used to determine its psychometric properties.

\section{Procedure}

The design of this study was approved by Institute Review Board (IRB), translation of Nepali Maharajgunj Medical Campus, Tribhuvan University Teaching Hospital. The permission was taken from the administrative level and teachers of selected different schools. Pre-schooler children were considered eligible for the study if they were 3- 6 years old and their mother who were willing to participate. A sealed envelope containing a request letter to parents, an informed consent form, and Nepali version of the Preschool Anxiety Scale were sent to parents through the school authority. The questionnaires returned by parents were collected from the school administration.

\section{Data analysis}

Analyses were carried out using SPSS V.20. Confirmatory factor structure was conducted with SPSS AMOS 21.0 for five correlated factors original model of PAS provide a good fit of data for the Nepalese sample by the means of the following criteria: (CMIN/DF(16) with a value equal to 5; GFI (17) value is greater than 0.80; NFI (16) values is greater than 0.90; CFI (18) value is greater than 0.90; RMSEA(19) value is less than $0.06(18), \mathrm{RMR}(18)$ value is less than 0.06 .

\section{Results}

Socio-demographics status (Mother) and total PAS score: shows statistically significant with education of the mothers $[\chi 2$ (d.f.,5) $=15.84, p=0.007$ ] and occupation of the mothers $[\chi 2$ (df.,5) $=20.899, p<0.001$ and family types $\chi 2(d f, 1)=8.607, p=0.003$ ]. However, the total PAS score was insignificant with different age groups $[\chi 2$ (d.f.,5) = 7.299, $p=0.199$ ], religion [ $\chi 2$ (d.f.,4) $=7.673, p=0.104]$, Caste $[\chi 2(d . f ., 9)=24.021$, $p=0.004]$.

Socio-demographics status and total PAS score (Preschool Children) especially related to child shows statistically significant with age groups of children $[\chi 2(d . f ., 3)=8.747, p=0.033]$ and gender $[\chi 2(d . f ., 1)=$ 6.547, $p=0.01]$.

\section{Exploratory Factor Analysis}

A Principal Axis Factoring with a varimax (Kaiser Normalization) rotation was conducted using the 28 items on PAS. Kaiser-Meyer-Olkin (KMO) measure of sampling adequacy was determined to know whether the given responses with the sample are adequate or not. The KMO measure was 0.90 , which lies between $0.7-0.8$ and is above 0.5 indicating, "Acceptable" (20). The analysis yielded six factors with eigen value greater than 1 . Even the scree plot supports six factors. Factor loadings $<0.3$ were not been displayed as these were suppressed and the variables were listed in the order of size of their factor loadings as requested for the output to be sorted by size. 
Exploratory factor analysis using mother's response $(N=680)$ of 28 items produced six factors with an eigenvalue $>1$. Six factor varimax rotation produced factors relating to Factor 1: (eigenvalue $=6.921$; $24.718 \%$ variance); Factor 2: (eigenvalues $=1.967 ; 7.027 \%$ variance), Factor 3: (eigenvalues: 1.473 ; $5.259 \%$ variance), Factor 4: (eigenvalues: $1.345 ; 4.804 \%$ variance), Factor 5: (eigenvalue: $1.150,4.107 \%$ variance), Factor 6 : (eigenvalue: $1.087 ; 3.883 \%$ variance). The two factors were related to generalizing anxiety category of the original scale. Of the 28 items, 27 loads above 0.30 on the hypothesized factor. One item intended to measure compulsion "Washes his/her hands over and over many times each day" did not load significantly on any factor and has communality under 0.3 . The mean of this item was also low. Hence, this item can be removed. The first-factor physical injury was a bit mixture of items of separation anxiety. The second factor was separation anxiety which consisted mixture of items relating to obsessive-compulsive. The third factor was obsessive-compulsive consisted of items mixture of items relating to separation anxiety. The fourth factor was labelled as Social phobia. The fifth factor and Sixth factor were generalized anxiety consisted of items a mixture of items relating to social phobia.

Items that did not load on their hypothesized factor included are mentioned: The item "Is afraid of crowded or close-in places" loaded in physical injury fear and generalized anxiety. The item "Is reluctant to go to sleep without you or to sleep away from home" loaded in physical injury fear. The item "Is afraid of meeting or talking to unfamiliar people" loaded in physical injury fear and social phobia factor. The items "Has bad or silly thoughts or image that keep coming back over and over" and "Ask for reassurance when it doesn't seem necessary" loaded in separation anxiety. The item "Has to keep thinking special thoughts (e.g., numbers or words) to stop bad things from happening" loaded in separation anxiety and obsession and compulsion. The item "Is afraid to go up to a group of children and join their activities" loaded in separation anxiety and social phobia. The item "Worries that he/she will do something embarrassing in front of other people" loaded in separation anxiety, obsession compulsion, and social phobia. The two items "Worries that something bad will happen to his/her parents" and "Worries that something bad might happen to him/her" loaded in obsession and compulsion. The item "worries that he/she will do something to look stupid in front of other people" loaded in generalized anxiety. The item "Spends a large part of each day worrying about various things" loaded in separation anxiety and generalized anxiety. Thus, only 17 items loaded onto original factors. All of the items are presented in Table 1. (Table is included at last in the document). 
Table 1

(EFA) Factor loading of items on PAS with varimax rotation, Communalities

\begin{tabular}{|c|c|c|c|c|c|c|c|c|c|}
\hline & & & & 1 & 2 & 3 & 4 & 5 & 6 \\
\hline PIF & 7 & $\begin{array}{l}\text { Is scared of heights (high } \\
\text { places) }\end{array}$ & 0.37 & 0.61 & & & & & \\
\hline PIF & 20 & $\begin{array}{l}\text { Is afraid of insects and/or } \\
\text { spiders }\end{array}$ & 0.32 & 0.57 & & & & & \\
\hline PIF & 26 & Is afraid of the dark & 0.29 & 0.51 & & & & & \\
\hline PIF & 13 & Is scared of thunder storms... & 0.31 & 0.50 & & & & & \\
\hline PIF & 24 & Is frightened of dogs & 0.32 & 0.49 & & & & & \\
\hline PIF & 10 & $\begin{array}{l}\text { Is afraid of crowded or closed- } \\
\text { in places }\end{array}$ & 0.40 & 0.47 & & & & & 0.36 \\
\hline SA & 6 & $\begin{array}{l}\text { Is reluctant to go to sleep } \\
\text { without you or to sleep away } \\
\text { from home. }\end{array}$ & 0.192 & 0.43 & & & & & \\
\hline SOA & 11 & $\begin{array}{l}\text { Is afraid of meeting or talking } \\
\text { to unfamiliar people }\end{array}$ & 0.35 & 0.39 & & & 0.39 & & \\
\hline PIF & 17 & Is nervous of going swimming & 0.23 & 0.33 & & & & & \\
\hline SA & 25 & $\begin{array}{l}\text { Has nightmares about being } \\
\text { apart from you... }\end{array}$ & 0.43 & & 0.61 & & & & \\
\hline OC & 21 & $\begin{array}{l}\text { Has bad or silly thoughts or } \\
\text { images that keep coming back } \\
\text { over and over. }\end{array}$ & & & & & & & \\
\hline SA & 22 & $\begin{array}{l}\text { Becomes distressed about your } \\
\text { leaving him/her at } \\
\text { preschool/school or with a } \\
\text { babysitter }\end{array}$ & 0.36 & & 0.55 & & & & \\
\hline GA & 28 & $\begin{array}{l}\text { Asks for reassurance when it } \\
\text { doesn't seem necessary }\end{array}$ & 0.24 & & 0.46 & & & & \\
\hline OC & 27 & $\begin{array}{l}\text { Has to keep thinking special } \\
\text { thoughts (e.g., numbers or } \\
\text { words) to stop bad things from } \\
\text { happening... }\end{array}$ & 0.36 & & 0.44 & 0.37 & & & \\
\hline SOA & 23 & $\begin{array}{l}\text { Is afraid to go up to group of } \\
\text { children and join their activities }\end{array}$ & 0.27 & & 0.38 & & 0.34 & & \\
\hline
\end{tabular}

Source: Field study, 2019

Note: OC = obsession compulsive, GAD: Generalized Anxiety Disorder, SA=Separation Anxiety, SOA= Social Anxiety, PIF= Physical injury Fears 


\begin{tabular}{|c|c|c|c|c|c|c|c|c|}
\hline & & & 1 & 2 & 3 & 4 & 5 & 6 \\
\hline OCD & 18 & $\begin{array}{l}\text { Has to have things in exactly } \\
\text { the right order or position to } \\
\text { stop bad things from } \\
\text { happening }\end{array}$ & 0.31 & & 0.60 & & & \\
\hline OCD & 3 & $\begin{array}{l}\text { Keeps checking that he/she } \\
\text { has done things right (e.g., that } \\
\text { he/she closed a door, turned off } \\
\text { a tap) }\end{array}$ & 0.26 & & 0.53 & & & \\
\hline SOA & 19 & $\begin{array}{l}\text { Worries that he/she will do } \\
\text { something embarrassing in } \\
\text { front of other people }\end{array}$ & 0.40 & 0.35 & 0.45 & 0.34 & & \\
\hline SA & 12 & $\begin{array}{l}\text { Worries that something bad will } \\
\text { happen to his/her parents }\end{array}$ & 0.29 & & 0.41 & & & \\
\hline SA & 16 & $\begin{array}{l}\text { Worries that something bad } \\
\text { might happen to him/her. }\end{array}$ & 0.36 & & 0.36 & & & \\
\hline SOA & 15 & $\begin{array}{l}\text { Is afraid of talking in front of } \\
\text { the class (preschool group) e.g., } \\
\text { show and tell }\end{array}$ & 0.32 & & & 0.57 & & \\
\hline SOA & 5 & $\begin{array}{l}\text { Is scared to ask an adult for } \\
\text { help (e.g., a preschool or school } \\
\text { teacher) }\end{array}$ & 0.27 & & & 0.47 & & \\
\hline SOA & 2 & $\begin{array}{l}\text { Worries that he/she will do } \\
\text { something to look stupid in } \\
\text { front of other people }\end{array}$ & 0.30 & & & & 0.60 & \\
\hline GAD & 1 & $\begin{array}{l}\text { Has difficulty stopping } \\
\text { him/herself from worrying }\end{array}$ & 0.30 & & & & 0.57 & \\
\hline GAD & 4 & $\begin{array}{l}\text { Is tense, restless or irritable due } \\
\text { to worrying }\end{array}$ & 0.29 & & & & 0.39 & \\
\hline GAD & 8 & $\begin{array}{l}\text { Has trouble sleeping due to } \\
\text { worrying }\end{array}$ & 0.33 & & & & & 0.44 \\
\hline GAD & 14 & $\begin{array}{l}\text { Spends a large part of each day } \\
\text { worrying about various things }\end{array}$ & 0.30 & 0.35 & & & & 0.43 \\
\hline $\mathrm{OC}$ & 9 & $\begin{array}{l}\text { Washes his/her hands over and } \\
\text { over many times each day }\end{array}$ & 0.22 & & & & & \\
\hline \multicolumn{9}{|c|}{$\begin{array}{l}\text { Source: Field study, } 2019 \\
\text { Note: OC = obsession compulsive, GAD: Generalized Anxiety Disorder, SA=Separation Anxiety, SOA= } \\
\text { Social Anxiety, PIF= Physical injury Fears }\end{array}$} \\
\hline
\end{tabular}

\section{Confirmatory Factor Analysis}


Model 1 (Five factors original model): The five models (GAD, SOA, SA, PIF, and OC) proposed by Spence et al., (2001) was tested allowing correlations between factors. The model provided a poor fit for the data $(\mathrm{X} 2=1244.806, \mathrm{p}<0.000, \mathrm{NFI}=0.743, \mathrm{NNFI}=0.716, \mathrm{CFI}=0.798, \mathrm{RMR}=0.102, \mathrm{RMSEA}=0.06, \mathrm{CMIN} / \mathrm{DF}=$ $3.64, \mathrm{GFI}=0.875$ ). CFA using the original factor model revealed that 25 of the 28 items had loading in excess of 0.40 on the single factor, and another three items had a loading 0.30 . The three items are:

Item 3: Related to Obsession and compulsion- (Keeps checking that he/she has done things right (e.g., that he/she closed a door, turned off a tap)

Item 2: Related to Social Phobia - (Worries that he/she will do something to look stupid in front of other people

Item 22: Related to Separation anxiety: (Is reluctant to go to sleep without you or to sleep away from home)

Model 2 (Adjusted model): The original five factors models were adjusted by removing three items with Standardized Regression Weights less than 0.4. After this adjustment, this model shows better fit for the data as indicated by the indices $(\mathrm{X} 2=783.4, \mathrm{df}=260, \mathrm{p}<0.000, \mathrm{NFI}=0.816, \mathrm{NFI}=0.568, \mathrm{CFI}=0.868, \mathrm{RMR}$ $=0.85, \mathrm{RMSEA}=0.054, \mathrm{CMIN} / \mathrm{DF}=3, \mathrm{GFI}=0.91)$.

\section{Reliability Analysis Of Test Instrument}

The internal consistency (a) of Preschool Anxiety Scale (PAS) - Parent version of original scale (28 item version) and adjusted model (25 item version) in Nepalese context was 0.881 and 0.875 respectively which indicate the good range in Table 2 . In the original model, the internal consistency of the subscales ranged from poor to fair level: 0.65 for generalized anxiety; 0.67 for social phobia; 0.55 for obsessivecompulsive disorder; 0.69 for physical injury fears, and 0.62 for separation anxiety. 
Table 2

Internal consistency of PAS-Parent version

\begin{tabular}{|lllll|}
\hline & Original scale (28 items) & \multicolumn{2}{c|}{ Adjusted model (25 items) } \\
\hline & $\begin{array}{l}\text { Number of } \\
\text { items }\end{array}$ & $\begin{array}{l}\text { Cronbach } \\
\text { alpha }\end{array}$ & $\begin{array}{l}\text { Number of } \\
\text { items }\end{array}$ & Cronbach alpha \\
\hline $\begin{array}{l}\text { Generalized } \\
\text { anxiety }\end{array}$ & 5 & 0.65 & 5 & 0.63 \\
\hline Social phobia & 6 & 0.67 & 5 & 0.66 \\
\hline $\begin{array}{l}\text { Obsessive- } \\
\text { compulsive }\end{array}$ & 5 & 0.55 & 4 & 0.56 \\
\hline $\begin{array}{l}\text { Physical injury } \\
\text { fears }\end{array}$ & 7 & 0.69 & 7 & 0.75 \\
\hline Separation anxiety & 5 & 0.62 & 4 & 0.63 \\
\hline Total score & 28 & 0.88 & 25 & 0.87 \\
\hline
\end{tabular}

In the modified model, internal consistency of the subscales ranged from poor to fair level: 0.63 for generalized anxiety; 0.66 for social phobia; 0.56 for obsessive-compulsive disorder $(0.56) ; 0.75$ for physical injury fears; and 0.63 for separation anxiety.

Cross informant agreement (father and mother)

Table 3 shows parental agreement on various scales. Pearson's correlation was carried out to check the relationship between the parental ratings with each other. Parental agreement on generalized anxiety disorder $(r=0.375)$, social phobia $(r=0.312)$ indicate a weak positive correlation. Similarly, parental agreement in physical injury fear $(0.201)$ and separation anxiety $(r=0.247)$ indicate a very weak positive correlation. Parental agreement in OCD (-0.034) is almost negligible. 
Table 3

Parental agreement on various scales of PAS $(\mathrm{N}=50)$

\begin{tabular}{|c|c|c|c|c|c|c|}
\hline \multirow{2}{*}{ Fathers' report } & \multicolumn{6}{|c|}{ Mothers' report } \\
\hline & OCD & Social phobia & Sep Anxiety & Physical Injury fear & GAD & Total \\
\hline OCD & -.034 & $.382^{\star *}$ & .227 & $.495^{\star *}$ & $.346^{*}$ & .109 \\
\hline Social phobia & -.055 & $.312^{*}$ & .196 & $.427^{\star \star}$ & $.310^{*}$ & .044 \\
\hline Sep Anxiety & -.119 & .159 & .247 & .232 & $.318^{\star}$ & .115 \\
\hline Physical Injury fear & -.209 & .197 & $.467^{\star \star}$ & .201 & .270 & .012 \\
\hline GAD & -.054 & $.323^{*}$ & .259 & $.431^{\star *}$ & $.375^{\star \star}$ & $.349^{*}$ \\
\hline Total & -.141 & $.334^{*}$ & $.371^{\star \star}$ & $.428^{\star \star}$ & $.406^{\star \star}$ & .104 \\
\hline
\end{tabular}

$\star \star$. Correlation is significant at the 0.01 level (2-tailed).

*. Correlation is significant at the 0.05 level of significance (2-tailed)

Source: Field study, 2019

\section{Discussion}

The objective of the study was to examine the factorial structure and the psychometric properties of the PAS in a Nepalese sample of Preschool-aged children between 3 to 6 years old. The majority of the participants were mostly Hindu mothers between the age ranges of 26 to 30 years. They were mostly Brahmin and belongs to housewives. The majority of them were from joint families. The children were between the age group of 3-6 years. The difference in PAS scores across age groups was found to be statistically significant. Thus, the elevated level of anxiety symptoms in older children may be a response to the transition to kindergarten or school. As the child gets older there were higher scores on PAS. And hence there might be the need for separate age-specific norms or cut-off values for PAS scores. Similarly, findings have been reported in Australia and China $(10,11)$. The gender difference across PAS scales was found statistically significant in our study. However, some studies (15) revealed PAS score and subscale have no significant difference in gender of pre-schooler children. Exploratory factor analysis showed that 18 of 28 items loaded on proposed factors. The exploratory factor analyses suggested that preschool anxiety items loaded onto six factors. However, there was no clear distinction for certain themes such as separation anxiety, obsessive-compulsive anxiety, and social phobia. The two items intended to measure separation anxiety, "is reluctant to go sleep without parents and sleep away from home" loaded in physical injury fear factor. One possible explanation might be a cultural difference between Nepalese and western families; societies over here emphasize interdependence and value group harmony (21). When children are separated from the family the stress might be manifested in form of physical injury fears than the anxiety of separation. The two items intended to measure separation anxiety, "worries that 
something bad will happen to him/her parents" and "Worries that something bad might happen him/her" are loaded in obsession and compulsion. This can be explained by the fact that a child who could not develop independence and individualism in societal interaction might land believing that he is not competent enough to adapt well enough in a wide social context which might develop as distressing repeated thought (22). The item, "is afraid of meeting or talking to unfamiliar people" had similar loading (.39) with the physical injury fear and social phobia. Despite this, it would be justifiable to consider this item as a measure of social phobia. The item "Worries that he/she will do something to look stupid in front of other people" intended to measure social phobia but loaded in generalized anxiety. One possible explanation is that in the Nepalese context, socialization practices stress more on self-control, emotional restraint, and obedience to authority (23) which contribute to internalizing the issue of anxiety. One item "washes his/her hands over and over many times each day" did not load high on either of these factors. This problem was also reported to be rare among Australian preschool children and Chinese preschoolers (10)(11).

The confirmatory factor analyses suggested that PAS- Parent version 28 items reflect the dimensions of social phobia, separation anxiety, obsessive-compulsive disorder, fears of physical injury fear, and generalized anxiety, provide a poor fit of the data. However, the five factors correlated model was found to be a good fit in different studies conducted in Austrian, Romanian and Chinese $(10,11,13)$. Confirmatory Factor Analysis of five-factor models was adjusted by removing three items with Standardized Regression Weights less than 0.4. After this removal, the new model PAS- 25 shows a better fit for the data on the based-on mother report. The three items were: Keeps checking that he/she has done things right (obsessive-compulsive subscale), Worries that he/she will do something to look stupid in front of other people (social phobia subscale), Is reluctant to go to sleep without you or to sleep away from home (separation anxiety subscale). The items on keeping checking things for doing correctly have also been reported to be rare among Australian preschool children (10) and Chinese pre-schoolers (11). Regarding the items on worry about looking stupid in front of other people and reluctance to sleep without parents, there could be diverse meanings in our culture; and hence there might have been difficulty in comprehension (24). For instance, children in our society are allowed to sleep with their parents most of the time. And hence the question on reluctance to sleep without parents could be giving different meaning for Nepali mothers. In current study, Cronbach's alpha for 28 items Preschool anxiety Scale (PAS)-Parent version was 0.88 indicating good reliability. Cronbach's alpha (a) of the generalized anxiety (0.65), Social phobia (0.675), physical injury fears (0.695) and Separation anxiety (0.627) were in fair range. Obsessive -compulsive disorder has poor internal consistency, (0.56). The internal consistency of PAS in preschool children of China, Netherland and Portugal reported in similar range $(11,12)$. After removing three items, Cronbach's alpha (a)co-efficient for the Preschool anxiety Scale (PAS)-Parent version of 25 items in Nepalese context was 0.87 which was still in good range. The current research suggests that parents do not agree on the ratings of anxiety symptoms of their children, as the findings show weak positive correlation in all subscale. However, some studies reported higher agreement in the range of .60 to .75 (15). One possible explanation is that mothers and fathers have different exposures to children's problems. In our society, mothers are likely to be witnessing more symptoms than fathers. 
The current study has several limitations that must be acknowledged. First, the samples were recruited from a non-clinical sample, one should be cautious while generalizing this finding in a clinical setting. Second, the current study test-retest reliability and divergent validity were not examined in this study, and this should be the focus of future research. The third limitation of this study was based solely on the mothers' report for factor analysis. Further study using both informants, teacher reports, and other assessment methods (such as direct behavioural observation) could provide additional support for the scale (10). Finally, the present study focused on the original PAS; therefore, the modifications introduced in PAS-revised were not included in the study (15).

\section{Conclusion}

The Nepalese version of the PAS demonstrated to have good psychometric properties in a sample of three to six-year-old children. Age and gender differences across PAS scales were found to be statistically significant in mother's reports. Preliminary exploratory factor analyses results suggest that the items of the PAS- Nepalese version do not reflect the five categories in anxiety in a clear way. This is particular in separation anxiety, social phobia, and obsessive-compulsion. The Confirmatory factor analysis of PAS-28 items showed poor fit of five factor original model for the data. However, adjusted five -factor original model after removing three items (25-item version) showed better fit for the data. Cronbach's alpha for the PAS-Parent version scale was in good range (0.87). Cross informant agreement on the ratings of anxiety symptoms of children by the fathers and mothers was low, as reflected by weak positive correlation.

The PAS- Parent version could be considered as a potential instrument to screen and assess the type and severity of anxiety problems. However, it can be a good supporting tool for clinicians and researchers, as it is short and easy to administer.

\section{List Of Abbreviations}

AGFI: Adjusted Goodness of Fit Index

AMOS: Analysis of Moment Structures

ADAA: Anxiety Disorder Association America

APA: American Psychiatric Association

APA: American Psychology Association

CBCL: Child Behaviour Checklist

CFI: Comparative Fit Index

CMFWQ: Children's Moods, Fear and Worries Questionnaire 
CMIN: Chi-square equivalent in Confirmatory Factor Analysis

DSM: Diagnostic Statistical Manual

EFA: Exploratory Factor Analysis

CFA: Confirmatory Factor Analysis

EMBU: Egna Minne Betraffande Uppfostran

ERLS: Elliptical Re-estimated Least Squares

GAD: Generalized Anxiety Disorder

GFI: Goodness of Fit Index

GOF: Goodness of fit

KMO: Kaiser-Meyer-Olkin

LISREL: LInear Structural RELations

NFI: Normed Fit Index

NNFI: Non-Normed Fit Index

OCD: Obsessive-Compulsive Disorder

PAS: Preschool Anxiety Scale

PIF: Physical Injury Fear

RFI: Relative Fit Index

RMR: Root Mean Square Residual

RMSEA: Root Mean Square Error of Approximation

SEM: Structural Equation Modeling

SEP: Separation Anxiety Disorder

SOC: Social Anxiety Disorder

SPSS: Statistical Package for Social Sciences

SCAS: Spence Children's Anxiety Scale 
TLI: Tucker Lewis Index

WHO: World Health Organization

\section{Declarations}

\section{Ethical approval and consent to participate}

Prospective participants received oral and written information about the study and provided their written informed consent. All procedures were in accordance with the ethical standards of the responsible committee. The design of this study was approved by Institute Review Board (IRB), translation of Nepali Maharajgunj Medical Campus, Tribhuvan University Teaching Hospital. Ref no: 244(6-11-E)

Consent for publication

Not applicable. Participants are anonymous with no identifying data have been collected.

\section{Availability of data and materials}

Not applicable

\section{Competing interests}

The authors declare that they have no competing interests.

\section{Funding}

Funding of USD 840 was received from University Grants Nepal which was used to pay the fees to experts during the translation and review phase (Mphil-75/76-HS-3).

\section{Authors' information}

Sabina Maharjan,

Email: sabinamaharjan071@gmail.com

Dr. Mita Rana

Email: ranamita@yahoo.co.uk

Bidusha Neupane

Email: sabisa121@gmail.com

Sujan Rijal

Email: sujanrizal007@gmail.com 
Dr. Suraj Shakya

Email: surajshakya2002@yahoo.com

Mr. Pramesh Man Pradhan

Email: prameshman@yahoo.com

Dr. Saroj Prasad Ojha

Email:ojhasp@yahoo.com

Dr. Kamal Gautam

Email: drkamal.gautam@gmail.com

\section{Authors' contribution}

SM has developed the overall idea for the research study. SM and MR worked on data analysis. All authors (SM, MR, SR, and BN) contributed equally in all parts of the development of the manuscript. KG, SO and PP have further supported the preparation and finalization. All authors have read and agreed to the published version of the manuscript.

\section{Acknowledgments}

We extend our gratitude to everyone who helped in making this research a success.

\section{References}

1. Kessler RC, Coccaro EF, Fava M, Jaeger S, Jin R, Walters E. The prevalence and correlates of DSM-IV intermittent explosive disorder in the National Comorbidity Survey Replication. Arch Gen Psychiatry. 2006;63(6):669-78.

2. Whalen DJ, Sylvester CM, Luby JL. Depression and Anxiety in Preschoolers: A Review of the Past 7 Years. Child and Adolescent Psychiatric Clinics. 2017;26(3):503-22.

3. Merikangas KR, He JP, Burstein M, Swanson SA, Avenevoli S, Cui L, et al. Lifetime prevalence of mental disorders in U.S. adolescents: results from the National Comorbidity Survey ReplicationAdolescent Supplement (NCS-A). J Am Acad Child Adolesc Psychiatry. 2010;49(10):980-9.

4. Wichstrøm L, Berg-Nielsen TS, Angold A, Egger HL, Solheim E, Sveen TH. Prevalence of psychiatric disorders in preschoolers. J Child Psychol Psychiatry. 2012;53(6):695-705.

5. Costello EJ, Egger HL, Angold A. The developmental epidemiology of anxiety disorders: phenomenology, prevalence, and comorbidity. Child Adolesc Psychiatr Clin N Am. 2005;14(4):63148 , vii. 
6. Bufferd SJ, Dougherty LR, Carlson GA, Rose S, Klein DN. Psychiatric disorders in preschoolers: continuity from ages 3 to 6 . Am J Psychiatry. 2012;169(11):1157-64.

7. Bittner A, Egger HL, Erkanli A, Jane Costello E, Foley DL, Angold A. What do childhood anxiety disorders predict? Journal of Child Psychology and Psychiatry. 2007;48(12):1174-83.

8. Egger HL, Angold A. Common emotional and behavioral disorders in preschool children: presentation, nosology, and epidemiology. J Child Psychol Psychiatry. 2006;47(3-4):313-37.

9. Campbell SB. Behavior problems in preschool children: a review of recent research. J Child Psychol Psychiatry. 1995;36(1):113-49.

10. Spence SH, Rapee R, McDonald C, Ingram M. The structure of anxiety symptoms among preschoolers. Behav Res Ther. 2001;39(11):1293-316.

11. Wang M, Zhao J. Anxiety disorder symptoms in Chinese preschool children. Child Psychiatry Hum Dev. 2015;46(1):158-66.

12. Muris $P$, Mayer B, Freher NK, Duncan S, van den Hout A. Children's internal attributions of anxietyrelated physical symptoms: age-related patterns and the role of cognitive development and anxiety sensitivity. Child Psychiatry Hum Dev. 2010;41(5):535-48.

13. Benga $\mathrm{O}$, Tुincaş, I., Visu-Petra, L. Investigating the structure of anxiety symptoms among Romanian preschoolers using the Spence Preschool Anxiety Scales. Cognition brain behaviour: an interdisciplinary journal. 2010;XIV.

14. Broeren S, Muris P. The Relation Between Cognitive Development and Anxiety Phenomena in Children. J Child Fam Stud. 2009;18(6):702-9.

15. Edwards SL, Rapee RM, Kennedy SJ, Spence SH. The assessment of anxiety symptoms in preschoolaged children: the revised Preschool Anxiety Scale. J Clin Child Adolesc Psychol. 2010;39(3):400-9.

16. Bentler P, Bonett D. Significance Tests and Goodness-of-Fit in Analysis of Covariance Structures. Psychological Bulletin. 1980;88:588-606.

17. Sörbom KGJrD. LISREL VI, analysis of linear structural relationships by maximum likelihood, instrumental variables, and least squares methods: Mooresville, Ind.: Scientific Software, Inc., (1984 (1986 printing); 1984.

18. Hu Lt, Bentler PM. Cutoff criteria for fit indexes in covariance structure analysis: Conventional criteria versus new alternatives. Structural Equation Modeling: A Multidisciplinary Journal. 1999;6(1):1-55.

19. Browne MW, Cudeck R. Alternative Ways of Assessing Model Fit. Sociological Methods \& Research. 1992;21(2):230-58.

20. Kaiser HF. An index of factorial simplicity. Psychometrika. 1974;39(1):31-6.

21. Khambaty M, Parikh RM. Cultural aspects of anxiety disorders in India. Dialogues Clin Neurosci. 2017;19(2):117-26.

22. Zhao J, Xing X, Wang M. Psychometric properties of the Spence Children's Anxiety Scale (SCAS) in Mainland Chinese children and adolescents. J Anxiety Disord. 2012;26(7):728-36. 
23. Xie DL, Frederick T. L. A cross-cultural study of anxiety among chinese and caucasian american university students. Journal of multicultural counseling and development. 2008;v36 n1 12.

24. Essau CA, Lewinsohn PM, Olaya B, Seeley JR. Anxiety disorders in adolescents and psychosocial outcomes at age 30. J Affect Disord. 2014;163:125-32. 